\title{
PELATIHAN PENULISAN ARTIKEL ILMIAH BAGI MAHASISWA TINGKAT AKHIR
}

\author{
Lisnawita ${ }^{1}$, Lucky Lhaura Van FC $^{2}$, Musfawati ${ }^{3}$ \\ $1,2,3$ Universitas Lancang Kuning, Pekanbaru, Indonesia \\ Jalan Yos Sudarso KM. 08 Rumbai, Pekanbaru-Riau, (0761) 53108 -53236 \\ email ${ }^{1}$ Lisnawita@unilak.ac.id, ${ }^{2}$ Lucky@unilak.ac.id, ${ }^{3}$ Musfawati@unilak.ac.id
}

\begin{abstract}
Abstrak: Fakultas Ilmu Komputer-Universitas Lancang kuning berdiri tahun 2006, dengan dua prodi yaitu prodi teknik informatika dan sistem informasi dengan Nomor SK pendirian PS : 2875/D/T2006, Visi dari fakultas ilmu komputer yaitu: "Menjadi fakultas ilmu komputer unggul diwilayah sumatera berlandaskan nilainilai budaya melayu pada tahun 2025", dan salah satu tujuannya yaitu: Menghasilkan karya-karya ilmiah dibidang komputer yang bermutu dan dapat dipublikasikan pada jurnal-jurnal dan seminar-seminar ilmiah. pada pengabdian ini dilakukan dengan demonstrasi. Pelatihan ini dapat membantu mahasiswa meningkatkan pemahaman dalam menulis artikel ilmiah serta Memberikan pemahaman kepada mahasiwa dalam memilih target jurnal yang akan dituju, sehingga saat membuat artikel bisa menyesuaikan selingkung dari jurnal yang dituju. Metode yang dilakukan dengan ceramah dan sesi tanya jawab serta pratek register dan submit artikel. Hasil Kegiatan pelatihan yang dilaksanakan sesuai dengan tujuan yang ingin dicapai yaitu meningkatkan pengetahuan dan kemampuan peserta sebesar $62,24 \%$.
\end{abstract}

Kata Kunci: Artikel, IImiah, Mahasiswa

\begin{abstract}
:
Faculty of Computer Science-Lancang Kuning University was founded in 2006, with two study programs, namely the informatics engineering and information systems study program with the PS establishment SK Number: 2875 / D / T2006, The vision of the computer science faculty is: "To become a superior faculty of computer science in the region of Sumatra based on the values of Malay culture by 2025", and one of its objectives, namely: Producing quality scientific works in the field of computers and can be published in scientific journals and seminars. at this dedication carried out by demonstration. This training can help students improve their understanding in writing scientific articles and Provide understanding to students in choosing the target journal to be aimed at, so that when making articles they can adjust the environment of the intended journal. The method is done by lecturing and question and answer sessions as well as practice registering and submitting articles. Results The training activities were carried out in accordance with the objectives to be achieved, namely increasing the knowledge and abilities of participants by $62.24 \%$.
\end{abstract}

\section{Keywords:}

\section{Pendahuluan}

Fakultas Ilmu Komputer-Universitas Lancang kuning berdiri tahun 2006, dengan dua prodi yaitu prodi teknik informatika dan sistem informasi dengan Nomor SK pendirian PS : 2875/D/T2006, Visi dari fakultas ilmu komputer yaitu: "Menjadi fakultas ilmu komputer unggul diwilayah sumatera berlandaskan nilai-nilai budaya melayu pada tahun 2025", dan Tujuan nya salah satunya yaitu: Menghasilkan karya-karya ilmiah dibidang komputer yang bermutu dan dapat dipublikasikan pada jurnal-jurnal dan seminar-seminar ilmiah.

Fakultas ilmu komputer dalam mewujudkan misi tersebut selalu berbenah agar visi pada tahun 2025 tercapai, terutama dibidang penelitian baik bagi dosen maupun bagi mahasiswa diwajibkan publikasi hasil penelitian nya pada jurnal-jurnal nasional maupun international. Secara keseluruhan para dosen sudah mempublikasikan hasil penelitian pada jurnal-jurnal nasional maupun international. 


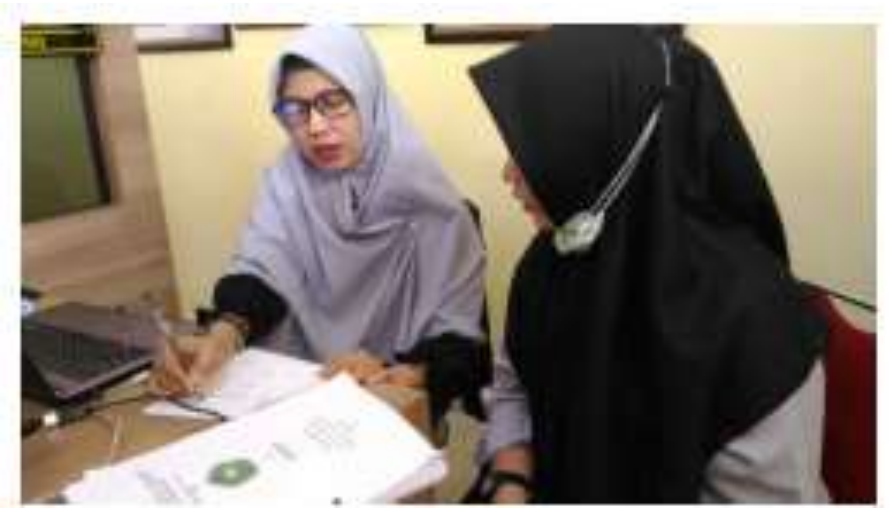

Gambar1: Mahasiswa sedang Bimbingan

Dari Gambar1 terlihat mahasiswa yang sedang bimbingan skripsi. Berdasarkan wawancara dengan mahasiswa yang sedang menyelesaikan skripsinya hanya beberapa orang saja yang sudah mempublikasikan hasil penelitiannya pada jurnal nasional yang ber ISSN. Ini disebabkan Mahasiswa belum begitu paham dalam membuat sebuah artikel, mahasiswa juga kurang memahami selingkung dari sebuah jurnal.

\section{Metode}

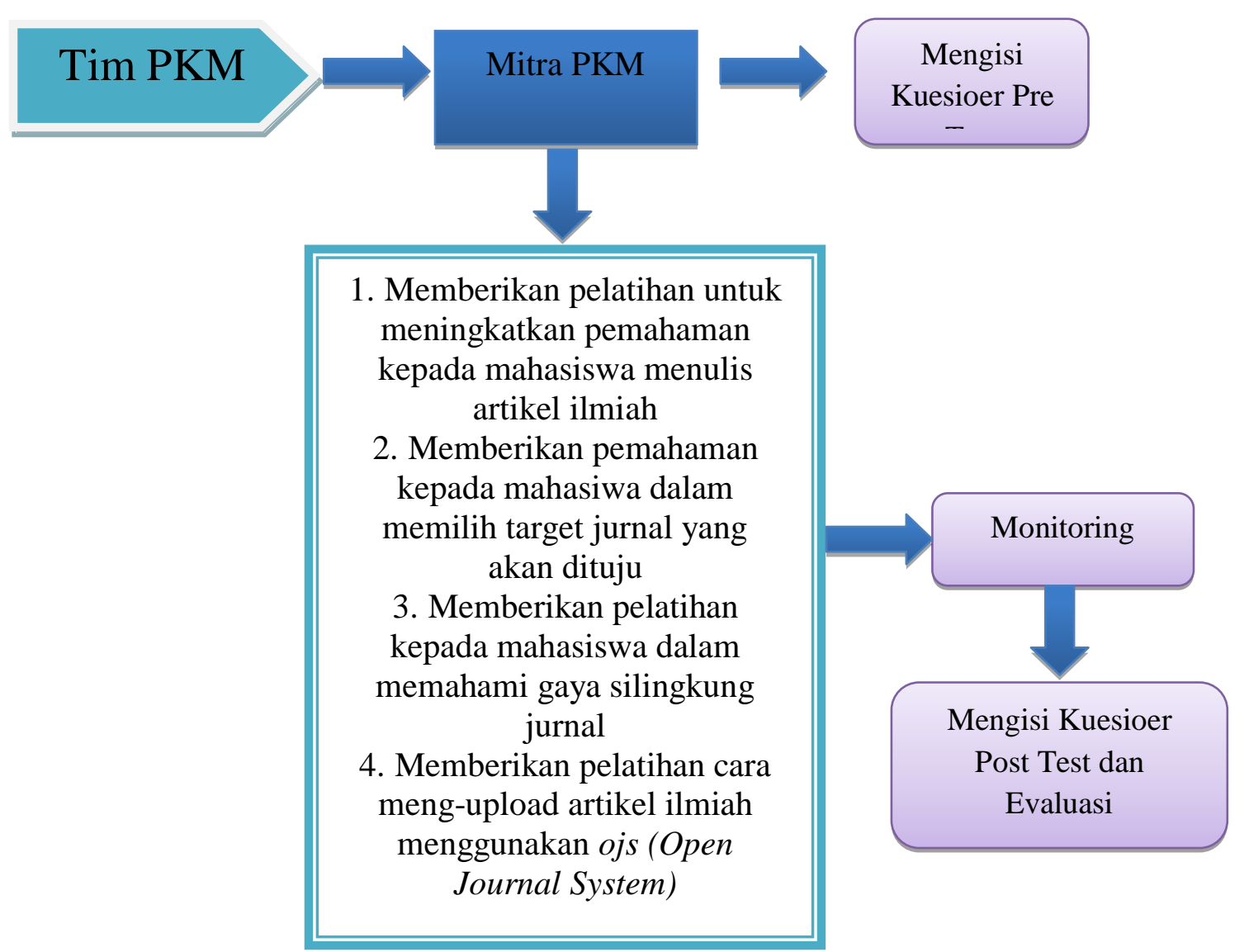

Gambar 2. Kerangka Pemecahan Masalah 
1. Pertama, tim pengabdian memberikan kuesioner (PreTest) untuk mengetahui pemahaman dengan materi yang akan di sampaikan nantinya.

2. Kedua yaitu Memberikan fase penyuluhan, setiap peserta akan diberikan pengarahan terlebih dahulu mengenai penulidan artikel ilmiah OJS dan manfaatnya. Metode yang digunakan adalah ceramah dan diskusi.

3. Ketiga yaitu fase demonstrasi dan pelatihan (praktek). Setiap peserta akan diberikan modul mendaftar dan upload artikel untuk memudahkan berlangsungnya pelatihan, Hingga peserta bisa Memahami dalam Menggunakan OJS

4. Terakhir yaitu fase evaluasi, evaluasi yang dilakukan pada kegiatan ini meliputi :

a. Evaluasi proses, dilakukan pada saat kegiatan sedang berlangsung. Aktivitas yang dievaluasi adalah dari minat peserta untuk melakukan tanya jawab dan diskusi mengenai tema pelatihan yang disajikan.

b. Evaluasi hasil, dilakukan dengan meminta mahasiswa untuk mempraktekkan cara register dan submit artikel pada OJS

c. Pada akhir kegiatan setiap peserta akan diberikan kuesioner (Post Test) untuk diisi sebagai evaluasi tim pengabdi di tahap akhir dan sebagai indikator keberhasilan dari pelatihan yang telah dilakukan.

\section{Hasil dan Pembahasan}

Kegiatan pengabdian ini dilaksanakan pada Ruangan Robotic Fakultas Ilmu Komputer Universitas Lancang Kuning dengan memajang Spanduk kegiatan yang menandakan adanya kegiatan pengabdian pada masyarakat sedang berlangsung. Kegiatan pelatihan dimulai pada pukul 14.00 WIB sampai dengan pukul 16.30 WIB dengan dihadiri oleh peserta 15 orang peserta. Setiap peserta pelatihan dibekali Modul Penulisan Artikel ilmiah bagi mahasiswa tingkat Akhir untuk memandu peserta dalam penulisan artikel ilmiah . Pada awal kegiatan Peserta mengisi Pre-Test untuk memahami tingkat pengetahuan sebelum dilakukan pelatihan. Selanjutnya kegiatan dibuka dan pemateri menjelaskan tentang artikel ilmiah dan memaparkan tentang manfaat dari pembuatan artikel ilimah. Langkah selanjutnya pemateri melanjutkan memaparkan tentang tips dalam menulis karya ilmiah, Kemudian dilanjutkan dengan cara register dan submit artikel pada OJS.

Setiap demonstrasi yang dilakukan pemateri akan diikuti praktek langsung oleh para peserta. Selama proses kegiatan peserta banyak memberikan pertanyaan terkait materi yang disajikan, hal ini menandakan keantusiasan para peserta pelatihan. Di akhir kegiatan dilakukan evaluasi, dengan memberikan Kuesinoner (Post test) untuk diisi oleh peserta. Tingkat keberhasilan atau evaluasi dari program kegiatan pengabdian diukur melalui kuesioner yang diberikan kepada peserta di akhir pelatihan dengan menggunakan skala Guttman. Yaitu skala yang menginginkan tipe jawaban tegas, seperti jawaban benar - salah, ya - tidak, pernah - tidak pernah, positif - negative, tinggi - rendah, baik - buruk, dan seterusnya. Pada skala Guttman, hanya ada dua interval, Yaitu Setuju dan tidak setuju.

Skala Guttman dapat dibuat dalam bentuk pilihan ganda maupun daftar checklist. Untuk jawaban positif seperti benar, ya, tinggi, baik, dan semacamnya diberi skor 1; sedangkan untuk jawaban negative seperti salah, tidak, rendah, buruk, dan semacamnya diberi skor 0. Pada Pengabdian ini diikuti oleh Responden sebanyak 13 orang, Berikut hasil perhitungan dengan menggunakan skala Guttman pada tabel 1. 
Tabel 1. Total Jawaban Responden Pre - Test

\begin{tabular}{|c|l|c|c|c|c|c|c|c|c|c|c|c|}
\hline No & \multicolumn{1}{|c}{ Responden } & P1 & P2 & P3 & P4 & P5 & P6 & P7 & P8 & P9 & P10 & P11 \\
\hline 1 & Arief Hidayat & 0 & 1 & 0 & 0 & 1 & 0 & 0 & 0 & 1 & 0 & 0 \\
\hline 2 & T.Usnikar & 1 & 1 & 1 & 0 & 0 & 1 & 1 & 1 & 1 & 0 & 0 \\
\hline 3 & Ismael & 0 & 0 & 0 & 0 & 0 & 0 & 0 & 0 & 0 & 0 & 0 \\
\hline 4 & Eko Wibowo & 1 & 1 & 0 & 0 & 0 & 0 & 0 & 0 & 0 & 0 & 0 \\
\hline 5 & Septian Noer Ali & 1 & 1 & 0 & 1 & 0 & 0 & 0 & 0 & 0 & 0 & 0 \\
\hline 6 & Bona & 0 & 0 & 0 & 0 & 0 & 0 & 0 & 0 & 0 & 0 & 0 \\
\hline 7 & Agus Irwandi & 0 & 1 & 0 & 0 & 0 & 1 & 1 & 0 & 0 & 0 & 0 \\
\hline 8 & Rizki Jumadian & 1 & 1 & 0 & 0 & 0 & 0 & 0 & 0 & 0 & 0 & 0 \\
\hline 9 & Fuad Reanadi & 1 & 0 & 0 & 0 & 0 & 0 & 0 & 0 & 0 & 0 & 0 \\
\hline 10 & Meriyati & 0 & 0 & 0 & 0 & 0 & 0 & 0 & 0 & 0 & 0 & 0 \\
\hline 11 & Teresia Elnra P & 0 & 0 & 0 & 0 & 0 & 0 & 0 & 0 & 0 & 0 & 0 \\
\hline 12 & Syahriwal & 1 & 0 & 0 & 1 & 0 & 0 & 0 & 0 & 1 & 0 & 0 \\
\hline 13 & Fajarudin & 1 & 1 & 0 & 0 & 0 & 1 & 0 & 1 & 1 & 0 & 0 \\
\hline
\end{tabular}

Perhitungan Jawaban "ya" dari angket:

Jawaban "ya" rata-rata : 2,31/11x100 = 20,98 \%

Pengetahuan Awal: 20,98 \%

Tabel 2. Persentase Pengetahuan Responden Post -Test

\begin{tabular}{|c|l|c|c|c|c|c|c|c|c|c|c|c|}
\hline No & \multicolumn{1}{|c}{ Responden } & P1 & P2 & P3 & P4 & P5 & P6 & P7 & P8 & P9 & P10 & P11 \\
\hline 1 & Arief Hidayat & 1 & 1 & 1 & 1 & 0 & 1 & 1 & 0 & 1 & 1 & 1 \\
\hline 2 & T.Usnikar & 1 & 1 & 0 & 1 & 1 & 1 & 0 & 0 & 1 & 0 & 0 \\
\hline 3 & Ismael & 1 & 1 & 1 & 1 & 0 & 1 & 0 & 1 & 1 & 1 & 0 \\
\hline 4 & Eko Wibowo & 1 & 1 & 1 & 1 & 0 & 1 & 1 & 0 & 1 & 1 & 1 \\
\hline 5 & Septian Noer Ali & 1 & 1 & 1 & 1 & 1 & 1 & 1 & 1 & 1 & 1 & 1 \\
\hline 6 & Bona & 1 & 1 & 1 & 1 & 1 & 1 & 1 & 1 & 1 & 1 & 1 \\
\hline 7 & Agus Irwandi & 1 & 1 & 1 & 1 & 1 & 1 & 1 & 1 & 1 & 1 & 1 \\
\hline 8 & Rizki Jumadian & 1 & 1 & 1 & 0 & 1 & 0 & 1 & 1 & 1 & 0 & 0 \\
\hline 9 & Fuad Reanadi & 1 & 1 & 0 & 1 & 1 & 1 & 0 & 0 & 1 & 1 & 1 \\
\hline 10 & Meriyati & 1 & 1 & 1 & 1 & 1 & 1 & 0 & 1 & 1 & 1 & 1 \\
\hline 11 & Teresia Elnra P & 1 & 1 & 1 & 0 & 1 & 1 & 1 & 1 & 1 & 1 & 1 \\
\hline 12 & Syahriwal & 1 & 1 & 1 & 1 & 0 & 1 & 0 & 1 & 1 & 1 & 1 \\
\hline 13 & Fajarudin & 1 & 1 & 1 & 1 & 1 & 1 & 1 & 1 & 1 & 1 & 1 \\
\hline
\end{tabular}

Perhitungan Jawaban "ya" dari angket:

Jawaban "ya" rata-rata : 9,15/11 x 100\% $=83,22 \%$

Jadi Pengetahuan 83,22 - 20,98 $=62,24 \%$

Berikut ini adalah foto selama kegiatan berlangsung

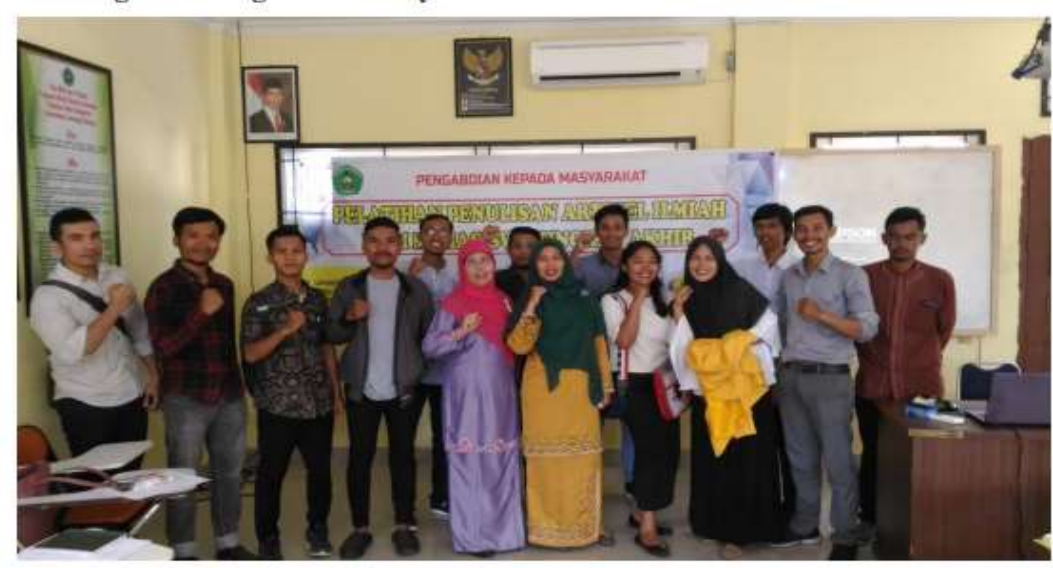

Gambar3: Peserta Pelatihan 


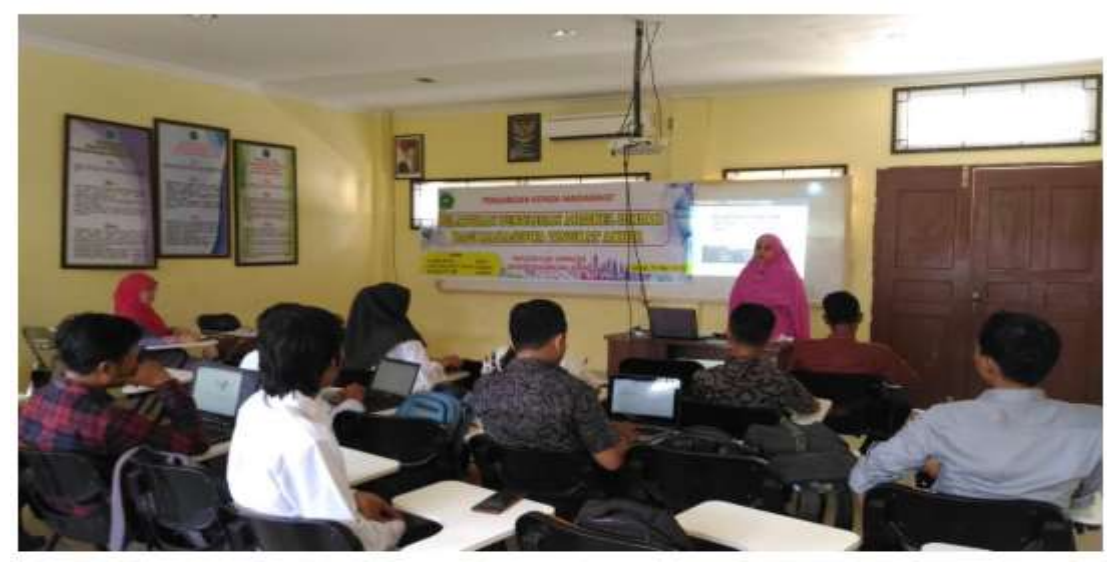

Gambar4: MC Membuka Kegiatan

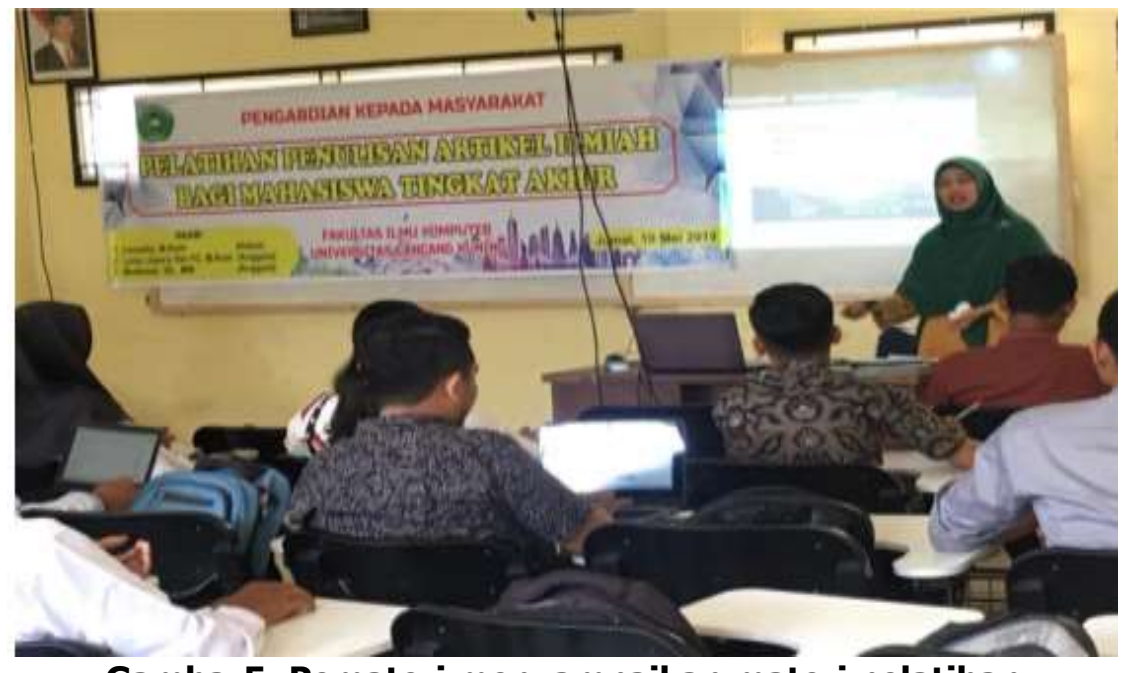

Gambar5: Pemateri menyampaikan materi pelatihan

\section{Kesimpulan}

Hasil dari evaluasi atau kuesioner yang diberikan kepada peserta maka diperoleh kesimpulan bahwa : Kegiatan pelatihan yang dilaksanakan sesuai dengan tujuan yang ingin dicapai yaitu meningkatkan pengetahuan dan kemampuan peserta dalam dalam penulisan Artikel sebesar 62,24\%. Peserta mampu mempraktekkan cara register dan submit jurnal pada OJS

\section{Ucapan Terima Kasih}

Terima akasih kepada Fakultas Ilmu Komputer Universitas Lancang Kuning yang telah membantu secara financial dalam pelaksanaan kegiatan Pengabdian Kepada Masyarakat ini

\section{Daftar Pustaka}

Darmalaksana, W., Suryana, Y., Studi, P., Hadits, T., Pendidikan, J., \& Islam, A. (n.d.). Korespondensi dalam publikasi ilmiah, 1-8.

Endang Sri Mujiwati,Erwin Putera Permana,Sutrisno Sahari, Novi Nitya Santi, Rian Damariswara,Bagus Amirul Mukmin, Farida Nurlaila Zunaidah, Kukuh Andri Aka, K. 
S. (2017). Pelatihan penulisan karya ilmiah untuk guru sekolah dasar pada anggota gugus 1 kecamatan ringinrejo. Abdinus, 1(1).

Febry Ichwan Butsi, A. N. (2017). Pelatihan tips dan trik submit artikel ilmiah di jurnal berbasis online. Amaliyah: Jurnal Pengabdian Kepada Masyarakat, 1(1), 49-51.

Lisnawita, L., Lucky Lhaura Van FC, \& Musfawati. (2020). Pelatihan Desain Grafis Untuk Meningkatkan Kreatifitas Siswa . Dinamisia : Jurnal Pengabdian Kepada Masyarakat, 4(2), 231-235

Mansyur, U., Sastra, F., \& Indonesia, U. M. (2018). Korelasi minat baca dengan kemampuan menulis karya tulis ilmiah mahasiswa pendidikan bahasa indonesia. Jurnal Perspektif, 2(1), 1-8.

Nafri Yanti, Suhartono, \& F. H. (2018). Keterampilan menulis akademik mahasiswa S-1 Program Studi Pendidikan Bahasa dan Sastra Indonesia. Silampari Bisa: Jurnal Penelitian Pendidikan Bahasa Indonesia, Daerah, Dan Asing, 1-16.

Rahmiati. (2014). Analisis kendala internal mahasiswa dalam menulis karya ilmiah. ALDaulah, 3(2).

Sudirman AM., M.Demsi Dupri, H. P. (2017). Peningkatan keterampilan menulis artikel ilmiah bagi guru di sekolah muhammadiyah. Sinar Sang Surya, 1(1), 14- 24.

Wardani, K., \& Azizah, D. M. (2018). Optimalisasi penulisan karya tulis ilmiah pada guru sd negeri jetis 2 yogyakarta. Abdimas Dewantara, 1(1), 77-86 